\title{
Festetics de Tolna en Océanie de Roger Boulay
}

\section{Gilles Bounoure}

\section{OpenEdition}

\section{Journals}

Édition électronique

URL : http://journals.openedition.org/jso/2032

DOI : 10.4000/jso.2032

ISSN : 1760-7256

Éditeur

Société des océanistes

Édition imprimée

Date de publication : 15 décembre 2008

Pagination : 339

ISBN : 978-2-85430-012-3

ISSN : 0300-953x

Référence électronique

Gilles Bounoure, "Festetics de Tolna en Océanie de Roger Boulay », Journal de la Société des Océanistes [En ligne], 126-127 | Année 2008, mis en ligne le 01 décembre 2008, consulté le 24 septembre 2020. URL : http://journals.openedition.org/jso/2032 ; DOI : https://doi.org/10.4000/jso.2032

Ce document a été généré automatiquement le 24 septembre 2020

(c) Tous droits réservés 


\title{
Festetics de Tolna en Océanie de Roger Boulay
}

\author{
Gilles Bounoure
}

\section{RÉFÉRENCE}

Roger Boulay (éd.), Festetics de Tolna en Océanie, avec la participation d'Élise PatoleEdoumba, La Rochelle, Rumeur des Âges, 124 p., illustrations dans le texte, noir et blanc et couleur, carte.

1 L'éditeur de cette publication élégante et sobre entend « apporter un complément utile au catalogue L'Aristocrate et ses cannibales " paru à l'occasion de l'exposition du même nom au musée du quai Branly (voir par ailleurs dans ce Jso). Il est de fait peu vraisemblable que les deux volumes de 1903 et 1904 où le comte Festetics narrait son périple soient jamais réédités intégralement, notamment parce que leurs illustrations décevraient le public actuel, et seuls des extraits très succincts avaient pu en être donnés dans le catalogue précité. La vingtaine de longues citations (dix pages pour l'escale de Choiseul, par exemple) qu'a retenues Roger Boulay pour le présent ouvrage offre un échantillon très représentatif de la narration «romanesque » (Boulay) et des poses avantageuses de Festetics, mais aussi de «l'ambiance du voyage » (Boulay) et des collectes ethnographiques justifiant cette croisière. Festetics les ayant pratiquées "surtout dans l'archipel du Vanuatu, aux îles Salomon et dans l'archipel Bismarck », c'est cette partie de la Mélanésie insulaire qu'intéressent la grande majorité des «morceaux choisis» par Roger Boulay. Mais le livre réserve à ses lecteurs d'autres " compléments utiles", en tête et en fin de volume, avec deux contributions portant sur l'histoire des objets collectés par Festetics et apportés par lui en France.

2 S'appuyant sur ses recherches dans l'ensemble des musées français, l'introduction de Roger Boulay présente des informations que n'avait pu accueillir le catalogue de l'exposition parisienne, par exemple à propos de certaines pièces océaniennes de la collection Girardin (Musée d'art moderne de la Ville de Paris) jadis décrites par Jean 
Guiart. Dans l'appendice, Élise Patole-Edoumba, responsable des collections ethnographiques et archéologiques du Muséum de La Rochelle, précise les circonstances d'entrée dans les collections publiques rochelaises d'une grosse centaine d'objets rapportés par le Tolna, dont elle reproduit et commente une sélection de douze pièces, pour certaines susceptibles d'études supplémentaires. Ainsi du beau collier « de Kaniet », en coquillages et fragments de vertèbres de requin, figuré p. 111 et sur la couverture; il est très semblable (nombre identique de pendentifs, notamment) à un collier de Ninigo reproduit par Georg Thilenius (Ethnographische Ergebnisse aus Melanesien, II, Ehrhardt Karras, Halle, 1903 : 241-2, fig. 80) qui en a aussi observé et rapporté la fabrication. Mais si Thilenius a effectivement séjourné à Ninigo et à Kaniet, en mars ou avril 1899 (grâce à Max Thiel et à la firme Hernsheim), Festetics assure au contraire avoir quitté Manus pour rejoindre le Japon, trois ans plus tôt, sans autre escale océanienne $(1904: 146,151)$. Où et comment s'est-il procuré le collier de La Rochelle? Sur cet exemple et quelques autres qu'aurait pu exploiter Alexandre Dumas, on voit aussi les aspects «romanesques » de l'enquête lancée par Roger Boulay sur les collectes de Festetics, comme si un certain « esprit d'aventure » s'était attaché à chacun des objets océaniens rapportés par le Tolna. 